\title{
The Effectiveness of Using the Analytic Scoring Approach on Developing the Speaking Skills of the Candidates for the IELTS Exam
}

\begin{abstract}
Sally Mohamed Saad El-Din Mostafa
English Language Lecturer, Department of Basic Sciences

Modern Academy for Engineering and Technology

\section{Abstract:}

The purpose of this research is to develop the speaking skills of the candidate language learners for the IELTS exam through the analytic scoring approach. The participants of the study included 30 students who were randomly chosen and divided into two groups: treatment $(N=15)$ and non-treatment $(N=15)$. The treatment group received instruction using the analytic scoring approach with its six aspects: appropriateness, organization of ideas, fluency, grammatical accuracy and structures, vocabulary and pronunciation. On the other hand, non-treatment group received their regular instruction. The instruments of the study were; an observation sheet designed as an oral quiz sheet and a scoring speaking rubric designed and modified to assess the language learners' speaking performance. Data were collected and t-test was used for the statistical analysis. Results indicated that there was a statistically significant difference between the mean scores of the treatment and nontreatment groups in the IELTS speaking test sample favoring the treatment group. It was concluded that the present research provided evidence for the effect of the analytic scoring approach on developing the candidate language learners' speaking skills for the IELTS exam.
\end{abstract}

Key words: Analytic scoring, speaking skills, speaking rubrics, IELTS exam. Introduction:

Speaking is one of the most difficult skills language learners have to face. It is considered a central skill. It is generally thought to be the most important, disappointing and frustrating of the four language skills to the EFL learners, as they have spent years studying English, yet still can not speak it. Murugaiah (2016) mentions that speaking is the most complex skill to acquire, as language has to be produced fluently, quickly and without planning which requires a great deal of time and effort for a foreign language learner to master the speaking skills. Pokrivcakoa (2010) asserts that many foreign language teachers and learners deem speaking skills as the measure of knowing a language. Brown (1994), similarly, labels speaking as the most challenging skill for students because of the set of features that characterize oral discourse: a) contractions, vowel reductions and elision; b) the use of slang and idioms; c) stress, rhythm and intonation; and d) the need to interact with at least one other speaker. Harmer (2007) explains that when speaking; words and phrases with individual sounds are constructed, also pitch change, intonation and stress are used to convey different meanings. Speakers can vary their intonation and stress to show the most important parts of their speeches. Speakers can also rephrase what they are saying by either speeding up or slowing down, also they can use a variety of body gestures and facial expressions to express their words. 
The Effectiveness of Using the Analytic Scoring Approach on Developing the Speaking Skills of the Candidates for the IELTS Exam

Assessing speaking is an intricate task. Luoma (2004) maintains a cycle of assessing speaking, as she claims that there should be an interaction in the assessment. She also specifies the different participants in testing an oral performance as examinees, interlocutors, raters and score users.

According to Bygate (2003), it is inevitable to enable the students to differentiate between their knowledge about a language and the skill to use it. As a result, language learners deal with what they learnt, processed sounds, and words to compose oral outcomes for specific purposes appropriate to the context in which it occurs. Such a process involves the participants, the experience, the physical environment and the purposes for speaking (Baker and Westrup, 2003). Analytic approach in testing speaking examines various features of the test separately, scoring each independently (Richards and Schmidt, 2013). Analytic assessment can be defined as a comprehensive scoring approach which assesses examinee's performance on three major dimensions which are separate delivery; language use and topic development (Ounis, 2017). It is also argued that the analytic scoring schemes are means of assessment that break down the objective of final products into criteria parts; such as content, organization, cohesion, register, vocabulary, grammar or mechanics; which are scored independently (Park, 2004).

As far as the assessment of oral proficiency is concerned, O'Sullivani (2012) maintains that the tests of spoken language ability are the most difficult to administer. Chuang (2009) explains that this difficulty may be related to the existence of many internal and external factors which affect the assessors. Luoma (Op. Cit), similarly, assures that assessing speaking is challenging because of the factors which may influence the impression of an assessor in terms of how well a person can speak. Furthermore, assessors expect accurate and appropriate test scores for the purposes of evaluating spoken proficiency.

Bueno Madrid and Mclaren (2006) have mentioned that most English teachers had spend all their classrooms teaching writing, reading and sometimes listening in a second language to their students, this is because grammar has a long written tradition, but according to their words, they do not pay attention to teach speaking and improve it as a skill.

\section{The context of the problem:}

The researcher has been teaching the IELTS (Academic / General), International TOEFL preparation courses and conversational English courses for almost 10 years. All of these courses are taught for adult language learners at different ages. While conducting these courses and practicing the language, the researcher noticed that speaking has been an obstacle for most of the language learners; as they were unable and unaware of how to launch a discussion or respond to a question. Language learners might be hesitant, shy, embarrassed, ignorant with responses, or confused with vocabulary choice. 


\section{Sally Mohamed Saad El-Din Mostafa}

The researcher conducted a pilot study among 30 language learners, who were getting prepared to pass the IELTS speaking test. They were asked to speak for two minutes about familiar topics related to their own lives and jobs, after preparing and organizing their ideas in just one minute. The results revealed that the language learners could understand the topic, but they could not produce or master the speaking skill; as no real communication was possible except for the most basic information using isolated words or short formulae in familiar situations to meet immediate needs.

The aim of this research was to examine if the analytic scoring approach in assessment, with its six basic components would be effective for improving the language learners' speaking performance.

Based on the above fore mentioned discussion, the following research questions were proposed.

1) What are the speaking skills required to be improved by adult language learners?

2) What are the main categories/criteria of the analytic scoring approach in the assessment of language learners' speaking performance?

3) To what extent will the analytic scoring approach in assessment improve the language learners' speaking skills?

\section{Literature Review:}

Speaking is considered to be the most important active skill. It is defined as a collection of the micro-skills which include syntax, grammar, morphology, pragmatics or social language, semantics and phonology. Mckey (2006) has mentioned that speakers can not produce effective and appropriate outcomes until they have been exposed to some specific linguistic competences such as grammar, pronunciation and vocabulary as well as the sociolinguistic competence; such as register of the expressions and the contextualizing of the language. According to his words, teachers were used to focus on teaching grammar and vocabulary in isolation which made it difficult if impossible for both teachers and assessors to assess language use ability. Ashour (2014) in her thesis has stated that language learners should recognize that speaking involves three areas of knowledge which are: a) mechanics (pronunciation, grammar and vocabulary); which is related to the usage of the right words in the right order with the correct pronunciation; b) function (transaction and interaction); knowing when clarity of message is essential and when precise understanding is not required; and c) social and cultural rules and norms (turn taking, rate of speech, length of pauses between speakers and relative roles of participants); realizing and bearing in mind who is the speaker, who is the listener, reasons and circumstances for speaking.

\section{Speaking Skills:}

1) Fluency: It is the feature of a second language oral performance that acts as a reliable indicator of how the speaker is efficiently able to mobilize and integrate, in a nearly simultaneous way, the underlying 
The Effectiveness of Using the Analytic Scoring Approach on Developing the Speaking Skills of the Candidates for the IELTS Exam

processes of planning and assembling an utterance in order to perform a communicatively acceptable speech act. (Segalewitz, 2010)

2) Pronunciation: Thombury (2005) defined it as the learner's capability to produce comprehensible utterances to fulfill the task requirements. In a wider meaning it is also defined as the production of significant sounds in terms of pure and meaningful sounds in contexts Dalton (1994).

3) Grammar: Parson (2004) defined it as a system of rules that regulates and controls the structure and arrangement of language. According to (Tomita, 1996) it facilitates the mapping between form and meaning, between the edges formed over words or phrases and their denotations in the system's world model.

4) Vocabulary: It is the most important objective of teaching and learning a second language. It starts from early childhood and develops continuously through adulthood serves communication.

5) Appropriateness: Kaplan (2010) defined it as the process of picking and choosing the content of communication as well as the formulation of the message based on the speaker's intention and cultural backgrounds.

In speaking, learners experience novel vocabulary and develop working knowledge of language form and structure once visually prompt and familiar information related to culture are provided. In oral learning, facing clues like intonation and gesture enhances understanding (Dawes, 2008).

According to (Jensen, Sandrock and Franklin, 2007) studying a certain amount of grammar and vocabulary does not help language learners to master the language, yet they need to employ the forms and the new vocabulary items into real life situations. The teacher's role has been shifted from building repertoire to teach and test items to building students' skills in using these items.

\section{Serious problems facing language learners in speaking English with high professionalism:}

A) Cultural differences: Speaking social roles and rules differ from one culture to another, which in turn influence the speakers' interest, ability, level of professionalism to learn speak or discuss with others. The barriers will appear when the language learners will transfer their cultural rules from their mother tongue language into the target language.

B) Personal differences: learners are categorized into different types, to overcome or at least reduce the amount of unwillingness to speak; learners are also diagnosed and sorted into different levels. Teachers 


\section{Sally Mohamed Saad El-Din Mostafa}

should treat them all the appropriate way, which helps them either improve or develop self-confidence.

C) Dealing with lack of confidence: lack of confidence and embarrassment are the main causes of unwillingness to speak. Teachers can help students to overcome their lack of confidence by offering them a supportive learning environment. On the other hand, language learners should feel free to ask questions, comment, add or even tell jokes so as to feel secure of making mistakes.

D) Limited time of speaking: Language learners at schools focus on examination papers which are written, even the speaking tasks are answered in the written form. It is also easier for teachers to correct mistakes of a written work than notice or observe in speaking, so they deal with speaking as an isolated skill while it can be a good practice for implementing new vocabulary and grammar Ashour, (2014).

\section{* Assessment of Speaking Skills:}

The difficulties in testing speaking oral skills frequently lead teachers into conducting inappropriate oral tests or even not testing speaking skills at all. Knight (2016) has identified a list of assessment criteria, which is fairly comprehensive in its broad categories. The list of the assessment criteria is as follows:
1) Grammar $\rightarrow$
a) range
b) accuracy

2) vocabulary $\rightarrow$
a) range
b) accuracy

3) pronunciation $\rightarrow$

a) individual sounds (phonemic distinctions)

b) stress and rhythm

c) intonation

d) linking /elision / assimilation

4) Fluency $\rightarrow$ a) speed of talking

b) hesitation while speaking

c) hesitation before speaking

5) Conversational skills $\rightarrow$

a) topic development

b) initiative (in turn taking and topic control)

c) cohesion:

i) with own utterances

ii) with interlocutor

d) Conversation maintenance: fillers)

(Clarification, repair, checking, pause

6) Socio linguistic skill $\rightarrow$

a) distinguishing, register and style (formal or in formal, persuasive or conciliatory)

b) use of cultural references.

7) Non-verbal $\rightarrow$

a) eye contact and body posture

b) gestures, facial expressions

8) Content $\rightarrow$

a) Coherence of arguments

b) relevance 
The Effectiveness of Using the Analytic Scoring Approach on Developing the Speaking Skills of the Candidates for the IELTS Exam

Chaung (2009) declares that assessing oral performance is the most difficult test to be carried out, as according to his words there exist many internal and external factors which affect assessors.

\section{Analytic scoring:}

Ouins (2017) has defined the analytic assessment as an alternative scoring approach which assesses language learners' performance in three dimensions which are separate delivery, language use and topic development. Park (2004) has argued that the analytic scoring schemes are means of assessment that work on by breaking down the objective of final products into criteria parts, where each of these parts is marked independently. The procedures of this approach of scoring involve the separation of the different features of a discourse into categories for marking purposes. The criteria that should be considered while assessing the speaking performance are content, organization, cohesion, register vocabulary, grammar or mechanics.

The analytical way of scoring provides ample sufficient information on the language ability of a candidate, or a language learner. It focuses attention on discrete qualities of the speaking performance, it separates the performance's features and evaluates each one individually and independently on its own subscale; combining scores on the apart subscales to produce an overall score for speaking; and sometimes reporting the sub scores to provide a richer level of source information, which in turn can be regarded useful for diagnostic purposes to guide future teaching and learning objectives (Taylor and Galaczi, 2011).

Analytic scoring schemes have both advantages and disadvantages. They are preferred by many speaking specialists for many reasons. First, they can be diagnostic to a great extent, as they can provide beneficial information about the language learners' speaking abilities. Learners are simply informed where their points of weaknesses and strengths are. Analytic scoring approach can be considered the most interpretable scoring approach as it determines the examinee's strengths and weaknesses; and identifies the speaking discourse's particular components that are needed to be developed by the examinees (Dowing and Haladyna, 2006). Analytic scoring scale provides teachers with the students' feedback related to the points or areas of weaknesses and strengths. The information provided by the analytic scores, can help the instructors and curriculum developers to set more close instructions to the students' needs.

According to Moskal (2000) the second advantage of analytic scoring is that it might be useful for second language learners, who are more likely to show a marked or uneven profile across different aspects of speaking discourse. Some 


\section{Sally Mohamed Saad El-Din Mostafa}

language learners may have excellent speaking skills, they can master the content and the organization of ideas, but on the other hand, they may make a lot of grammatical mistakes; others may have an excellent control of sentence structure, but may not know how to organize their speech in a logical way. On this aspect, the analytic scoring scales can help students to assess their progress in some or all the dimensions, especially if the same rubric categories are used.

Third, analytic schemes have also been found to be particularly beneficial for relatively inexperienced scorers. Weir (2005) claimed that a multi-trait analytic marking scheme is a useful tool for the new examiners' training and standardization.

Concerning the disadvantages of scoring analytically, the major disadvantage is that it takes too much time in rating speaking performance, as examiners are required to make more than one decision for every speaking performance. In analytic scoring, the examiner has to check, consider and score each criterion of the speaking ability giving a total score depending on the coefficient put forward. It was pointed out by the analytic scoring critics that measuring the quality of a text by tallying accumulated sub skill scores would diminish the inter connectedness of spoken discourse. Park (Op. Cit.) assured that measuring the quality of a spoken discourse by tallying accumulated sub skill would give the false impression that speaking could be understood and fairly assessed by analyzing autonomous discourse features. A false impression that speaking could be understood and fairly assessed by analyzing autonomous discourse features would be given by measuring the quality of a spoken discourse by tallying accumulated sub skill. Similarly, Hughes (1989) pinpointed that attention from the overall effect of the speech might be diverted by concentration on the different aspects. In as much as the whole is often greater than the sum of its parts, a composite score may be very reliable but not valid. In this aspect, the analytic scoring often has the tendencies to reduce and oversimplify the components of speaking, and to emphasize the flaws than the strengths of speaking.

According to (Hamp-lyous, 1989) there is an additional problem related to the analytic scoring schemes. As they pointed out that even experienced, essay judges sometimes find it difficult to assign numerical scores based on certain descriptors. In this aspect, there are possibilities for scorers to disagree with one another.

Pan (2016) has explained the dimensions for the assessment of spoken proficiency. Fluency, vocabulary and accuracy may be included in these dimensions, according to his words.

Council of Europe (2001) includes the following aspects of spoken language range, accuracy, fluency, interaction and coherence. It is also stated that pronunciation or intelligibility, fluency, accuracy and appropriateness are commonly used categories within speaking tests. Alternatively, Gondova 
The Effectiveness of Using the Analytic Scoring Approach on Developing the Speaking Skills of the Candidates for the IELTS Exam

(2014) explains that the following criteria are commonly used: appropriateness, organization of ideas, fluency, grammatical accuracy and range of grammatical structures, the range of vocabulary and its accuracy, content, pronunciation and intonation, and interaction. Grammar and vocabulary, discourse management, pronunciation and interactive communication are included in the analytical assessment scales within Cambridge English First Certificate (Cambridge English: Understanding Results Guide, 2014).

\section{Validity of the analytic scoring:}

In two different studies, Brown (2006a) (2006b), seeks to manifest the validity of the analytic rating scales in the Revised IELTS speaking test. In the first study, an empirical analysis to reflect the validity of the analytic rating scales on the ground of candidates' discourse is applied. The study's main aim is to verify the use of descriptors to define the score points on the scales. Accordingly, Brown analyses the speaking test band descriptors and criteria key indicators in order to highlight relevant analytic categories for each of the 4 band scales (pronunciation, fluency and coherence, grammatical range and accuracy, and lexical resources). The data for the analysis are drawn from twenty IELTS speaking test in various countries and with a range of proficiency levels. Although the study has some limitations on the grounds of scope, size and choice of analysis, the findings indicate that the overall outcomes of the study support the validity of the speaking test band descriptors.

In the second study, Brown (2006b) analyses the IELTS examiners' verbal reports and their responses to a subsequent questionnaire to investigate the validity (the interpretability and ease of application) of the analytic rating scales employed to assess candidates' performance in the Revised IELTS speaking test. The evidence reflects a relatively good rating procedure. The examiners' reports manifest their comfort and ease in employing the scales. Although examiners note some difficulties in making a clear distinction between scales and distinguishing levels, they report the consistency in their interpretations.

\section{The International English language Testing System (IELTS): Objectives of IELTS:}

The International English Language Testing System (IELTS) is currently one of the English tests of repute, which is employed to assess the language proficiency of candidates planning to study or work in contexts where English is employed as the language of communication. IELTS, nowadays, is recognized as a prerequisite for English medium study in higher education in most countries as well. Annually, more than 100,000 candidates participate IELTS at 251 approved British Council and IDP Education Australia Centers in over 105 countries. IELTS is employed to test all four language abilities of candidates. That is, reading, writing, listening and speaking. It sets out to assess 


\section{Sally Mohamed Saad El-Din Mostafa}

both academic and general English language proficiency of candidates. (Roshan, 2013). One of the popular techniques for the assessment of oral language proficiency is the conversational language proficiency interview. This kind of interview involves a face to face situation in which the interviewer queries a candidate on some specified topics. The belief behind this popular technique is that it allows the interviewer a context to test the candidate's communicative and interactional skills. Thus, the IELTS exam is regarded as a direct one (Brown, 2000).

\section{Description of the IELTS speaking test:}

The IELTS speaking test is taken in person with the examinee responding to questions face to face with an examiner. There are three sections of the speaking part. In terms of time, the test is short; it just takes between 11 to 14 minutes per examinee. The first section lasts for 4 to 6 minutes; where it is an interview in which the examinee is asked basic questions about familiar issues or topics. This section is designed to help the examinee to relax and talk naturally. This is a phase in which most candidates can easily engage, and in which their schematic knowledge can be activated.

In the second part, the examinee is given a task card, and after one minute of preparation time, he/she is expected to speak about the topic on the card for about one or two minutes without interruption. After finishing speaking, the examiner asks him/her one or two questions about the topic. Ellis (2003) points out that an opportunity for strategic planning can have a positive effect on both fluency and complexity as it allows speakers to conceptualize what they want to communicate rather than how to say it.

Finally, the third part of the exam, the examinee is asked some questions related to the topic from the previous section of the test, which enables the test taker an opportunity to expand upon the topic and speak about more abstract ideas. This phase deals with a two-way discussion in operating conditions. The candidates engage in an interactive communication with less predictable questions, which is very similar to what happens to candidates in real world situations.

During these three sections, the examiner is listening carefully; writing down notes using a pencil and paper; and recording the examinee's responses and answers for the marking purposes. Assessment criteria for the speaking test are based upon the following four features;

- Fluency and coherence: This refers to the test takers' ability to talk with normal levels of continuity, speech rate and effort, and to link ideas and language together in coherent, connected speech.

- Lexical resource: This refers to the range of vocabulary the test taker can use and how clearly meanings and attitudes can be expressed. This includes the range of words used and the ability to use fillers by expressing the idea in a different way. 
The Effectiveness of Using the Analytic Scoring Approach on Developing the Speaking Skills of the Candidates for the IELTS Exam

- Grammatical range and accuracy: This refers to the range of structures available to the test taker and how accurately and appropriately he/she can use them. Its assessment is based on the length and complexity of utterances as well as the effect of grammatical errors in communication.

- Pronunciation: This refers to the test takers' ability to produce comprehensible utterances and to use a range of pronunciation features to communicate meaning. Its assessment is based on how clear the candidate is to the listener and to what extent his/her language is influenced (Buriro, 2013).

\section{Validation of IELTS speaking test:}

One of the major strengths of IELTS Speaking test is the ongoing research on the various aspects of test. IELTS administration recognizes the need to address concerns on test validity and reliability, content/construct and facevalidity, ratings and raters. Therefore, it would be absolutely unfair to mention that after its revised version in July, (2001) on the basis of the studies, the administration has just stopped its interest for more research on the test but rather many researchers have been encouraged to explore possibilities for more improvements in the revised version and test material. Various researches are commendable for example, Read and Nation (2002) have investigated vocabulary use by candidates in the IELTS speaking test; by measuring lexical output, variation and sophistication, as well as the use of formulatic language. This study has explored the possibilities of the new research dimension; which has been addressed by Brown (2003) in her following study where she has examined the rating process in the revised IELTS speaking test and emphasizes on the need of raters training.

Another major strength of the speaking test is its emphasis on monitoring and standardization, the raters training and re-certification after every two years, which is great approach for maintaining the credibility and validity of the test, as validity according to Fulcher (2003) is not a one-time activity, but rather an ongoing process. As Chalhoub, Deville and Turner (2000) point out that IEILS differs from the Cambridge exams in that published reports recognize the need to address reliability and validity and include information to address it. They refer to the IELTS manuals, which describe a detailed approach to the certification of interviewers/assessors for the speaking test and raters for the writing component that requires re-certification procedures every two years.

The very format of IELTS speaking test, the direct interview is its key strength if compared to other speaking test formats such as in direct and semi-indirect interviews. Brown (2003) entailed three most outstanding features of direct interview, which are active participants, in the conversational exchange, opportunity to produce extended speech and candidates' chance to respond at length. Quain (2009) has identified another salient characteristic of interview, which is its high 


\section{Sally Mohamed Saad El-Din Mostafa}

authenticity through near authentic oral communication between the examiner and the examinee.

Despite the above-mentioned attempts in favor of the validity of the IELTS, other researchers have noted some demerits that should not be overlooked. Since IELTS has recognized itself as the international test of repute, therefore, weakness sounds a very harsh term for the test. However, researchers have shown some concerns over the parts of the test. One of the major concerns is pertaining to the connection between the test score and test taker's academic performance, which is found inconsistent by some of the studies. The connection between the test score and academic performance of the candidate was identified by Bayliss and Ingram (2006), as the study investigated some inconsistent results, which might be due to other variables that could influence the academic success and the fact is that IELTS only measures language proficiency. This point was endorsed as they found that performance in language test tasks can be influenced by a wide range of features, which can interact unpredictably with characteristics of individual test-takers.

Another concern is determined by Issitt (2008), that the speaking section of the IELTS test provokes more anxiety than the paper partitions. As the examiners have to perform individually in a very short time, often after having waited anxiously for their appointment. It seems reasonable that candidates could easily underperform if they let the situation depress them. Cultural constraints of the test takers and examiners were another concern raised by Cronjé (2009). He suspects that if test takers can not express well in the assessor's language, and if the assessor is not familiar with the cultural constraints within which students operate, it will be difficult for the assessor to collect evidence of appropriate performance.

Similarly, Khan (2006) has raised serious concerns over the element of biasness in IELTS speaking assessment. She has investigated and assessed that the IELTS speaking test has subtle cultural biases embedded in its structure, vocabulary patterns and methodology, background knowledge and vocabulary beyond the test-taker's range of experience and exposure. She further validates her point by stating that it is possible to identify positive and negative factors in oral performance. According to her, familiar tasks achieve greater accuracy.

\section{Research hypotheses:}

Based on the survey of the for mentioned literature the following research hypotheses could thus be formulated;

1) There would be a statistically significant difference between the mean scores of the treatment and non-treatment groups of the language learners in the speaking skills for the post IELTS speaking test sample in favor of the treatment group. 
The Effectiveness of Using the Analytic Scoring Approach on Developing the Speaking Skills of the Candidates for the IELTS Exam

2) There would be effectiveness for the analytic scoring approach in developing the speaking skills of the language learners, who are getting prepared for the IELTS exams.

3) There would be a statistically significant difference between the mean scores of the treatment and non-treatment groups of the candidates' language learners for the IELTS exam in the post administration of the observation sheet in favor of the treatment group.

4) There would be effectiveness for the analytic scoring approach through the administration of the observation sheet on developing the speaking skills of the candidate language learners for the IELTS exam.

\section{Methods and Procedures:}

\section{- Research Participants:}

The research participants included thirty (30) language learners, who were preparing themselves to be examined the IELTS exam. Those thirty participants were divided into two groups; treatment and non-treatment ones. Each group involved fifteen (15) language learners, the participants in both groups were approximately at the same age (from 21 to 23 years old); some of them were fresh graduates; others were seniors as they were still studying in the last year in their faculties. Some of the participants were preparing themselves to immigrate, while the others were going to apply for jobs that require passing the IELTS exam with score 7 out of 9 . All of the participants were studying the General IELTS preparation course; where they were asked to practice the four language skills. The thirty participants, 18 males and 12 females, had been administered a placement test by the researcher before joining the two groups for studying the General IELTS preparation course. The purpose of that placement test was to make sure that all of the language learners were nearly practicing the intermediate language level (I3) with the same proficiency, which has been recommended to join the course. The treatment group was taught to improve the speaking skills by the analytic scoring approach; while the non-treatment group was taught by the regular method.

\section{Instructor:}

The researcher conducted the experiment herself; as she has been teaching English conversational courses for adults for eighteen years and instructing the Academic/General IELTS and International TOEFL preparation courses for ten years.

The instructor is also a $\mathrm{PhD}$ holder in TEFL and is working as a lecturer in Modern Academy for Engineering and Technology.

\section{The IELTS Speaking Course:}

The whole preparation course for The IELTS test was taught and practiced in forty five hours, which lasted for five weeks; three sessions every week, each one of three hours. Twenty-five hours were specified for practicing the reading, 


\section{Sally Mohamed Saad El-Din Mostafa}

listening and writing skills while twenty hours were assigned for practicing only the speaking skill. By the end of these determined twenty hours, the language learners should respond fluently and express their opinions freely about general topics and issues; as they were subjected to answer both expected and unpredictable questions. The actual conduction of the speaking sessions went through four stages:

The first stage: Generating/Eliciting ideas:

1) The instructor would pick a general topic for being discussed; then she would write it on the board, asking the language learners to think of and elicit ideas related to this topic from their own perspectives.

2) The language learners were expected to start generating the ideas and write them on pieces of paper that were handed in to the instructor.

3) The instructor is supposed to organize the ideas with the language learners to help them recognize which ideas should come in first and which ones should come next; so that their responses and answers would be organized and convenient within the limitations and boundaries of the topic.

4) After discussing the ideas, the instructor would ask the language learners to prepare themselves in two minutes, as every one would have just three minutes to speak about that topic.

* The second stage: Oral Presentation (A):

$5)$ Every language learner is supposed to start speaking about the topic from his own perspective utilizing and applying his/her ideas and vocabulary that should be appropriate to the topic itself.

6) The instructor would record all these responses for scoring purposes, also she would take her notes that were related to the six main aspects of analytic scoring which were; appropriateness, organization of ideas, fluency, grammatical accuracy and structures, vocabulary and pronunciation. She identified and marked the mistakes in an oral quiz scoring sheet (See: appendix B). She also wrote down the most impressive words, idioms and expressions in the descriptive language produced by the learners.

\section{The third stage: Peer evaluation:}

7) The instructor would ask the language learners to evaluate each other. They also had the oral quiz scoring sheet to rate each other in the scale which identified the six aspects of the analytic scoring.

8) The instructor would play the audio recordings as she and all the language learners evaluated the speaker. Finally, they discussed the positive and the negative aspects with each other; which in turn helped the learners to improve their speaking skills that needed development and proficiency.

9) The instructor would provide the learners with reading passages related to the topic asking them to summarize these reading passages in their own words; making use of the vocabulary and their synonyms discussed in the session.

The fourth stage: Oral Presentation $(B)$ :

10) The language learners were asked to speak about that topic once more after being prepared to the next session; which helped the learners to be more 
The Effectiveness of Using the Analytic Scoring Approach on Developing the Speaking Skills of the Candidates for the IELTS Exam

self-confident, and get used to be asked in a foreign language and respond fluently.

\section{Class Setting:}

Approximately seven sessions were specified for practicing the speaking skills. In each session one topic was discussed by the learners; recorded, organized and explained by the instructor and another topic was prepared by the language learners for being discussed the next session. The topics that were debated among the language learners were as follows:

1) Your Country: Which part of your country do most people live in? What are the main industries in it? How easy is it to travel around your country? Has your country changed much since you were a child?

2) A well known person that the language learner liked or admired: Who is this person? What has this person done? Why is this person well-known? Why is he/she admired?

3) Famous people in your country and the idea of being in the public eye: What kind of people become famous these days? Are they different from famous people in the past? How do you think people will become famous in the future? What are the advantages and disadvantages of being famous? How does media in your country treat famous people?

4) Music and young people / Music and society: What kinds of music are popular with young people in your culture? What do you think influences a young person's taste in music? How has technology affected the kinds of music popular with young people? How important is it for a culture to have musical traditions? Why do you think countries have national anthems of songs?

5) Entertainment: Do you prefer relaxing at home or going out in the evening? why? When do you go out for an evening, what do you like to do? Is there any kind of entertainment you do not like? Why/Why not? If you are on a vacation, would you like to spend it indoors or outdoors? why?

6) Qualities of friends: Describe one of your friends, How do you spend time together? What do you think are the most important qualities for friends to have? What do you think causes friendships to break up?

7) Relationships among people: Who are the most important to people; their family or their friends? Why? What other types of relationships, a part from friends or family are important in people's lives today? Have relationships with neighbors where you have lived changed in the recent years ? How? How important do you think it is for a person to spend sometimes alone? Why / Why not?

8) Fashion and clothes: How important are clothes and fashion to you? Why/Why not? What kind of clothes do you dislike? Why? How different are the clothes you wear now from those you wore ten years ago? What do you think the clothes we wear say about us?

9) Festivals and celebrations: Describe a festival that is important in your country, When does the festival occur? What do you do during the festival?, What do you like or dislike about it?, What are the national or the 


\section{Sally Mohamed Saad El-Din Mostafa}

religious occasions in your country?, What are the people's customs in celebrating these occasions?

10) Festivals and the media: What role do the media play in festival? Do you think it is good or bad to watch festivals on TV? Why? How may globalization affect different festivals around the world?

11) Birthdays: Do you celebrate your birthday? How do you get prepared for that day? Is it a tradition in your country to organize parties for celebrating birthdays? What is the best or the worst present you received on your birthday?

\section{Study Instruments:}

1) An observation sheet, designed as an oral quiz scoring sheet, which is an adapted version of (Rickards, 2012) was employed in this research. The observation sheet included the six main aspects of the analytic scoring which were: appropriateness, organization of ideas, fluency, grammatical accuracy and structures, vocabulary and pronunciation (See: appendix B).

2) A scoring speaking rubric, adopted from CEP placement rubric, was designed, modified and employed in this research to assess the language learners' speaking performance according to the six aspects of the analytic scoring. (See: appendix D)

\section{Scoring / Rating:}

A scoring system, an observation sheet and a rubric were designed to assess the language learners' performance from one side, and from the other side the responses were recorded to evaluate the speaking skills of the participants. The language learners, who were getting prepared to the IELTS speaking exam, have been notified to take care of their facial expressions, body posture and selfconfidence while speaking and responding to the questions.

For scoring purposes the language learners were given (5) five points in all the fore mentioned items if they have fully operational command of language; appropriate, accurate and fluent with complete understanding. They can get (4) four points when they have operational command of the language, though with occasional inaccuracies, inappropriacies and misunderstandings in some situations. They can handle complex language well and understand detailed reasoning. (3) Three points were given to the modest language users, as they had partial command of the language, coping with overall meaning in the most situations, though are likely to make many mistakes. Limited language users were assigned (2) two points, as they convey and understand only general meaning in very familiar situations; frequent breakdowns in communication occur. Score (1) one was given to the non-language user; who had no ability to use the language beyond possibly a few isolated words. Zero score was assigned to the language learners who didn't attempt the sessions.

\section{Results of the research, discussion and interpretation:}

This part includes the results of the research and the discussion in the light of the research problem and the hypotheses. The results were obtained through administering the observation sheet and the IELTS speaking test sample. The 
The Effectiveness of Using the Analytic Scoring Approach on Developing the Speaking Skills of the Candidates for the IELTS Exam

test and the observation sheet were administered for both the treatment and non-treatment groups.

Pre-test results:

Comparison between the mean scores of the speaking skills required for the IELTS exam for both the treatment and non-treatment groups:

Table (1): Comparing the means scores of the required speaking skills for the IELTS exam for both the treatment and non-treatment groups:

\begin{tabular}{|l|c|c|c|c|c|c|l|}
\hline \multicolumn{1}{|c|}{ Group } & Number & Mean & SD & T & $\begin{array}{c}\text { Significance } \\
\text { level }\end{array}$ & df & Significance \\
\hline Treatment & 15 & 12.533 & 3.136 & 0.348 & 0.01 & 28 & $\begin{array}{l}\text { Non- } \\
\text { Significant }\end{array}$ \\
\hline $\begin{array}{l}\text { Non- } \\
\text { treatment }\end{array}$ & 15 & 12.133 & 3.159 & 0.348 & 0.01 & 28 & $\begin{array}{l}\text { Non- } \\
\text { Significant }\end{array}$ \\
\hline
\end{tabular}

The previous table showed that there was no statistically a significant difference between the mean scores of the treatment and non-treatment groups in the Pre/ IELTS speaking test sample; as their means were (12.533) and (12.133), which meant that they were at the same level before conducting the experiment. Also it was noticeable that (T-value) was not significant, as it was (0.348)

Post-test results: (In the light of the research hypotheses):

- Comparison between the results of the post IELTS speaking test sample for both the treatment and non-treatment groups:

Paired sample t-test was used to compare the performance of the treatment and non-treatment groups as the post IELTS speaking test sample in order to determine whether the language learners' speaking skills have been improved after conducting the analytic scoring approach. This was conducted by testing the first hypothesis of the research which stated that:

"There would be a statistically significant difference between the mean scores of the treatment and non-treatment groups of the language learners in the speaking skills for the post IELTS speaking test sample in favor of the treatment group."

Table (2): Comparing the results of the post IELTS speaking test sample for both the treatment and non-treatment groups:

\begin{tabular}{|l|c|c|c|c|c|c|c|}
\hline \multicolumn{1}{|c|}{ Group } & Number & Mean & SD & T & $\begin{array}{c}\text { Significance } \\
\text { level }\end{array}$ & df & Significance \\
\hline Treatment & 15 & 24.333 & 3.45 & 6.226 & 0.01 & 28 & Significant \\
\hline $\begin{array}{l}\text { Non- } \\
\text { treatment }\end{array}$ & 15 & 15.933 & 3.91 & 6.226 & 0.01 & 27.57 & Significant \\
\hline
\end{tabular}

This table shows that there was a statistically significant difference between the mean scores of the two groups favoring the treatment group. The mean score for the treatment group was higher than that of the non-treatment group, as it was (24.333) for the treatment and (15.933) to the non-treatment group. T- 


\section{Sally Mohamed Saad El-Din Mostafa}

value indicated that the language learners in the treatment group achieved progress and improvement, as it was (6.226) at significance level (0.01). So it can be concluded that the first hypothesis was accepted.

- Testing the effectiveness of the analytic scoring approach on developing the speaking skills of the candidate language learners for the IELTS exam:

To test the second hypothesis of the research; which stated: "There would be effectiveness for the analytic scoring approach in developing the speaking skills of the language learners who were getting prepared for the IELTS exam", the mean scores of the treatment group results were compared before and after conducting the experiment.

Results of the pre and post IELTS speaking sample test were calculated. Also $\eta^{2}$ and Es were calculated to examine how the analytic scoring approach with its six aspects affected the treatment's group performance of the speaking skills. One sample t-test was used.

Table (3): Testing the effectiveness of the analytic scoring approach on developing the speaking skills of the candidate language learners for the IELTS exam:

\begin{tabular}{|c|c|c|c|c|c|c|c|c|c|}
\hline Group & Measurement & $\mathbf{N}$ & Mean & SD & $\begin{array}{c}\text { T- } \\
\text { value }\end{array}$ & df & Significance & $\boldsymbol{\eta}^{\mathbf{2}}$ & Es \\
\hline Treatment & Pre-test & 15 & 12.533 & 3.136 & 0.348 & 28 & Sig. & \multirow{2}{*}{0.58} & 2.35 \\
\hline Treatment & Post-test & 15 & 24.333 & 3.457 & 6.226 & 28 & Sig. & & \\
\hline
\end{tabular}

The previous table showed that the analytic scoring approach proved to have a great effect on improving the speaking skills' performance of the language learners in the treatment group. T-value was highly significant, as it was (6.226) with freedom degree 28. $\eta^{2}$ and Es were calculated and they were high, as $\eta^{2}$ was $(0.58)$ and Es was (2.35) which declared the effectiveness of the analytic scoring approach, and as a result the second hypothesis was approved.

- Comparing between the mean scores and results of both the treatment and non-treatment groups in the post observation sheet administration:

To test the third hypothesis which stated that, "There would be a statistically significant difference between the mean scores of the treatment and nontreatment groups of candidate language learners for the IELTS exam in the administration of the post observation sheet in favor of the treatment group", Ttest was used to compare the results between the two groups.

Table (4): Comparing between the mean scores and results of both the treatment and non-treatment groups in the post observation sheet administration:

\begin{tabular}{|c|c|c|c|c|c|c|c|c|}
\hline Skills & Group & $\mathbf{N}$ & Mean & SD & Significance & $\mathbf{t}$ & df & Significance \\
\hline \multirow[t]{2}{*}{ 1) Appropriateness } & Treatment & 15 & 3.93 & 0.703 & \multirow[b]{2}{*}{0.01} & \multirow[b]{2}{*}{6.808} & \multirow[b]{2}{*}{28} & \multirow[b]{2}{*}{ Significant } \\
\hline & $\begin{array}{c}\text { Non- } \\
\text { treatment }\end{array}$ & 15 & 2.00 & 0.845 & & & & \\
\hline \multirow{2}{*}{$\begin{array}{l}\text { 2) Organization of } \\
\text { Ideas }\end{array}$} & Treatment & 15 & 4.20 & 0.774 & \multirow[b]{2}{*}{0.01} & \multirow[b]{2}{*}{7.89} & \multirow[b]{2}{*}{28} & \multirow[b]{2}{*}{ Significant } \\
\hline & $\begin{array}{c}\text { Non- } \\
\text { treatment }\end{array}$ & 15 & 1.93 & 0.798 & & & & \\
\hline 3) Fluency & Treatment & 15 & 4.20 & 0.774 & 0.01 & 5.602 & 28 & Significant \\
\hline
\end{tabular}


The Effectiveness of Using the Analytic Scoring Approach on Developing the Speaking Skills of the Candidates for the IELTS Exam

\begin{tabular}{|c|c|c|c|c|c|c|c|c|}
\hline & $\begin{array}{l}\text { Non- } \\
\text { treatment }\end{array}$ & 15 & 2.66 & 0.723 & & & & \\
\hline \multirow{2}{*}{$\begin{array}{l}\text { 4) Grammatical } \\
\text { accuracy and } \\
\text { Structure }\end{array}$} & Treatment & 15 & 4.066 & 0.798 & \multirow[b]{2}{*}{0.01} & \multirow[b]{2}{*}{3.638} & \multirow[b]{2}{*}{28} & \multirow[b]{2}{*}{ Significant } \\
\hline & $\begin{array}{c}\text { Non- } \\
\text { treatment }\end{array}$ & 15 & 3.066 & 0.703 & & & & \\
\hline \multirow[t]{2}{*}{ 5) Vocabulary } & Treatment & 15 & 4.00 & 0.925 & \multirow[b]{2}{*}{0.01} & \multirow[b]{2}{*}{2.824} & \multirow[b]{2}{*}{28} & \multirow[b]{2}{*}{ Significant } \\
\hline & $\begin{array}{c}\text { Non- } \\
\text { treatment }\end{array}$ & 15 & 3.066 & 0.883 & & & & \\
\hline \multirow[t]{2}{*}{ 6) Pronunciation } & Treatment & 15 & 3.933 & 1.279 & \multirow[b]{2}{*}{0.05} & \multirow[b]{2}{*}{1.788} & \multirow[b]{2}{*}{28} & \multirow[b]{2}{*}{ Significan } \\
\hline & $\begin{array}{c}\text { Non- } \\
\text { treatment }\end{array}$ & 15 & 3.20 & 0.941 & & & & \\
\hline
\end{tabular}

Table (4) above showed that the analytic scoring approach proved to have a great effect on developing the speaking skills of the treatment group. There was a statistically significant difference between the mean scores of both groups in all the skills; appropriateness, organization of ideas, fluency, grammatical accuracy and structures, vocabulary and pronunciation. The mean scores were very high for the treatment group language learners concerning the first three skills; as they were (3.93), (4.20), (4.20) respectively, while for the non treatment group of language learners were (2.00), (1.93), (2.26) respectively. Tvalue was also very high in the first three skills, as it ranged from (5.62) up to (7.98).

There was also a statistically significant difference between the mean scores of the treatment and non-treatment groups in the other three skills; which were grammatical accuracy and structure, vocabulary and pronunciation. But the mean scores and t-value were not as high as those of the first three skills (appropriateness, organization of ideas and fluency). The mean scores for the treatment group language learners were (4.066), (4.00) and (3.933) respectively, while those of the non-treatment group were (3.066), (3.066) and (3.20) respectively. Also T-value - ranged from (1.788) in the sixth skill, to (2.824) in the fifth skill and reached to (3.638) in the fourth skill. These data revealed that there was a high difference between both groups in the first three skills. This difference is related to the administration of the analytic scoring approach; as the language learners were taught how to organize their ideas; to keep the appropriateness and to stay in topic, also how to speak fluently by using the analytic scoring approach. The other three skills were also developed but not with a very high difference when compared with the first three skills. This is because all the language learners in both groups were nearly with the same proficiency in practicing the language. As mastering the skills of grammatical accuracy and structures, vocabulary and pronunciation was a must to join the IELTS preparation course. And although the language learners in both groups were qualified enough in practicing these skills, but there was also a difference in the mean scores in favor of the treatment group after administering the analytic scoring approach. 


\section{Sally Mohamed Saad El-Din Mostafa}

- Testing the effectiveness of the analytic scoring approach on developing the speaking skills of the candidate language learners for the IELTS exam through the use of the observation sheet:

To test the fourth hypothesis of the research which stated that "There would be an effectiveness for the analytic scoring approach through the administration of the observation sheet on developing the speaking skills of candidate language learners for the IEITS exam." The mean scores of the treatment and non-treatment groups were calculated. These mean scores were of the post administration of the observation sheet, which included the six aspects of the analytic scoring approach. $\eta^{2}$ and Es were also calculated to examine how the analytic scoring approach affected the speaking skills of the language learners.

Table (5): Testing the effectiveness of the analytic scoring approach on developing the speaking skills of the candidate language learners for the IELTS exam through the use of the observation sheet:

\begin{tabular}{|l|c|c|c|c|c|c|c|c|}
\hline \multicolumn{1}{|c|}{ Skills } & $\mathbf{N}$ & Mean & SD & $\begin{array}{c}\text { T- } \\
\text { value }\end{array}$ & df & $\boldsymbol{\eta}^{\mathbf{2}}$ & Es & $\begin{array}{c}\text { Significance } \\
\text { level }\end{array}$ \\
\hline 1) Appropriateness & 15 & 3.93 & 0.703 & 6.808 & 28 & 0.62 & 2.27 & 0.01 \\
\hline $\begin{array}{l}\text { 2) Organization of } \\
\text { Ideas }\end{array}$ & 15 & 4.20 & 0.774 & 7.98 & 28 & 0.69 & 2.94 & 0.01 \\
\hline 3) Fluency & 15 & 4.20 & 0.774 & 5.602 & 28 & 0.53 & 2.12 & 0.01 \\
\hline $\begin{array}{l}\text { 4) Grammatical } \\
\text { accuracy and } \\
\text { Stricture }\end{array}$ & 15 & 4.066 & 0.798 & 3.638 & 28 & 0.32 & 1.4 & 0.01 \\
\hline 5) Vocabulary & 15 & 4.00 & 0.925 & 2.824 & 28 & 0.22 & 1.06 & 0.01 \\
\hline 6) Pronunciation & 15 & 3.933 & 1.297 & 1.788 & 28 & 0.10 & 0.67 & 0.05 \\
\hline
\end{tabular}

The analytic scoring approach had a great effect on developing the speaking skills of the language learners in the treatment group. T-value and the mean scores were high. Also $\eta^{2}$ and Es when calculated, they were high to prove the effectiveness of the analytic scoring approach. It is also noticeable from the table that $\eta^{2}$ and Es were higher, concerning the first three skills, than their values for skills four, five and six.

As $\eta^{2}$ values for the first three skills; appropriateness, organization of ideas and fluency; were (0.62), (0.69) and (0.53) respectively. On the other hand when $\eta^{2}$ was calculated for the other skills, grammatical accuracy and structures, vocabulary and pronunciation, the values were lower, as they were (0.33), (0.22), (0.10) respectively. The same results were obtained when Es values were calculated, as they were (2.27), (2.94) and (2.12) respectively for the first three skills; and (1.4), (1.06) and (0.67) for the next three skills respectively. These results indicated that the effectiveness of the analytic scoring approach on the first three skills (appropriateness, organization of ideas and fluency) was higher than its effectiveness on the grammatical accuracy and structure, vocabulary and pronunciation skills. This would be attributed to the 
The Effectiveness of Using the Analytic Scoring Approach on Developing the Speaking Skills of the Candidates for the IELTS Exam

proficiency of the language learners in practicing the language and mastering skills four, five and six. As they all had a good command of English, but the problem was how to stay in topic, organize the ideas and speak fluently. So, it can be concluded that the analytic scoring approach had effectiveness on developing the speaking skills mentioned in the observation sheet, and so the fourth hypothesis was accepted.

\section{Conclusions, Recommendations and Suggestions:}

The present part provides conclusions based on the study findings drawn from the results, which in turn, are drawn from the statistical data analysis. It also presents some recommendations and finally suggests some areas for further research.

\section{- From the results it could be concluded that:}

1) The analytic scoring approach is highly effective on developing the speaking skills of the language learners as; appropriateness; organization of ideas; fluency; grammatical accuracy and structures; vocabulary and pronunciation.

2) The observation sheet, designed as an oral quiz scoring sheet, played an important role on developing the speaking skills of the language learners in the treatment group, as it included all the six aspects of the analytic scoring approach with gradual rating that helped the instructor to assign the scores.

3) Peer evaluation among the language learners of the treatment group was a highly an effective strategy to develop the speaking skills. As every language learner was aware not only of his mistakes, but also of the others' faults; which in turn helped to improve the skills faster.

4) Peer evaluation and the usage of the oral quiz scoring sheet; which included the six aspects of the analytic scoring approach, enabled the language learners to realize how the speaking test is scored. As a result they realized how they lose and miss marks while speaking because they actually played the rater's role.

\section{Recommendations:}

- The following recommendations can be proposed:

1) Picking and selecting general topics for being discussed; either these topics are related or unrelated to the language learners' culture, would be effective for generating and eliciting new ideas.

2) Asking the language learners to express their ideas in pieces of paper and hand them in to the instructor helped the language learners to elicit freely different and various ideas from their own perspectives.

3) Writing the ideas on the board and discussing them with the language learners helped them to organize their ideas better.

4) The idea of recording the language learners' talks helped them listen carefully to themselves and realize their defects or difficulties while speaking. 


\section{Sally Mohamed Saad El-Din Mostafa}

5) The language learners' participation in scoring made them interactive and alert all the sessions, also they became aware of how the scoring process was performed.

6) Providing the language learners with reading passages related to the topics they discussed was also useful and beneficial. Language learners were able to use new structures, idioms, varied sentences, propositional phrases, determiners as well as vocabulary and their synonyms that helped them to speak fluently and to be more self-confident.

\section{- Suggestions for further research:}

1- It is suggested to conduct a study to investigate the effectiveness of the analytic scoring approach on teaching the writing skills; as its six aspects would help to improve the writing skills for candidate language learners for the IELTS exam.

2- Analytic scoring could be applied for rating, scoring the speaking skills of pupils in elementary schools, and then improving their speaking skills.

3- A comparison between the analytic and holistic scoring approaches could be made to select the more accurate approach for scoring the speaking skills of the language learners' examinees in the International TOEFL test (IBT).

4) The analytic scoring approach could be used to improve the writing skills of the pupils in the elementary school. 
The Effectiveness of Using the Analytic Scoring Approach on Developing the Speaking Skills of the Candidates for the IELTS Exam

\section{References}

Ashour, J.M. (2014). The Effect of Using a Video Conferencing - Based Strategy on UNRWA $9^{\text {th }}$ Graders' English Speaking Skills and their Attitudes Towards Speaking. Master Thesis. Faculty of Education. The Islamic University of Gaza.

Baker, J. and Westrup, H. (2003). Essential Speaking Skills: A Handbook for Language Teachers. London: Continuum. Inc.

Bayliss, A. and Ingram, D.E. (2006). IELTS as a Predictor of Academic Language Performance. Paper Presented at International Educational Conference.

Brown, A. (2000). An Investigation of the Rating Process in the IELTS Oral Interview. Research Reports, 3, 49-85. Retrieved from www:ielts.org/PDF/ vol 3- Report 3.pdf.

Brown, A. (2003). Interviewer Variation and the Co-construction of Speaking Proficiency. Language Testing, 20(1), 1-25.

Brown, A. (2006a). Candidate Discourse in the Revised IELTS Speaking test. IELTS Research Reports IELTS Australia and British Council. (vol.6, PP.1-19) Retrieved from http://www.ielts.org/pdf/ volume \%206, \%20 Report \%203 pdf.

Brown, A. (2006b). An Examination of Rating process in the Revised IELTS Speaking Test. IELTS Research Reports IELTS Australia and British Council. (vol.6, PP. 1-30) Retrieved from http://www.ilets. org/researchers/ research/ ilets speaking test.aspx.

Brown, H. D. (1994). Teaching by Principles: An Interactive Approach to Language pedagogy. Englewood Cliffs, NJ: Prentice Hall Regents.

Bueno, A. D. Madrid and N. Mclaren, (eds). (2006). TEFL in Secondary Education. Granada: Editorial University de Granada.

Buriro, G.S., (2013). Analysis of a Test or Assessment Procedure for IELTS Speaking Test. International Journal of English and Education. Volume 2, Issue 3.

Bygate, M. (2003). Speaking (10 $10^{\text {th }}$ ed.). New York: Oxford University Press.

Challhoub. Deville, M. and Turner, C.E. (2000). What to look for in ESL Admission Tests: Cambridge Certificate Exams, IELTS, and TOEFL. System, 28, 523539.

Chuang, Y. (2009). Foreign Language Speaking Assessment: Tairvanese College English Teachers' Scoring Performance in the Holistic and Analytic Rating Methods. The Asian EFL Journal, 11 (1), 150- 173.

Cronje, J.C. (2009). Qualitative Assessment Across Language Barriers: An Action Research Study. Educational Technology and Society. 12(2), 69-85.

Dalton, C. and Seidlhofer, B. (1994). Pronunciation. Oxford University Press: Oxford.

Dawes, L. (2008). The Essential Speaking and Listening. Oxon: Routledge.

Downing, S.M. and Haladyna, T.M. (2006). Handbook of Test Development. New Jersy: Lawrence Erlbaum Associates, Inc.

Ellis, R. (2003). Task-Based Language Learning and Teaching. Oxford University Press. 


\section{Sally Mohamed Saad El-Din Mostafa}

Fulcher, G. (2003). Testing Second Language Speaking. Harlow; Pearson Education Limited.

Gondova. D. (2014). Taking First Steps in Teaching English: Assessing Learners. Zilina: EDIS.

Hamp-lyons, L. (1989). Second Language Writing: Assessment Issues. In Kroll, B. (Ed.), Second Language Writing. Cambridge: Cambridge University Press. Pp. 69-87.

Harmer, J. (2007). The Practice of English Language Teaching. $4^{\text {th }}$ ed. London: Longman.

Hughes, A. (1989/2003): Testing for Language Teachers. Cambridge: Cambridge University Press.

Issitt, S. (2008). Improving Scores on the IELTS Speaking Test. ELT Journal. 62(2), 131-138.

Jensen, J., Sandrock, P. and Franklin, J. (2007). The Essentials of World Languages, Grades K-12: Effective Curriculum Instruction, and Assessment. Aexandria: ASCD.

Kaplan, R. (2010). The Oxford Handbook of Applied Linguistics. Oxford: Oxford University press.

Khan, R. (2006). The IELTS Speaking Test: Analysis Cultural Bias. Malaysian Journal of ELT Research, 2, 60-79.

Knight, B. (2016). Assessing Speaking Skills: A Workshop for Teacher Development. ELT Journal. July 1992. Volume 4013. Oxford University Press. Available at: http://www.researchgate. net/

Luoma, S. (2004). Assessing Speaking U.K: Cambridge University Press.

McKay, P. (2006). Assessing young Language Learners. Cambridge: Cambridge University Press.

Mckay, S. (2002). Teaching English as An International language. New York: Oxford University Press.

Moskal, B.M. (2000). Scoring Rubrics: What, When and How? Practical Assessment, Research and Evaluation, 7(3). Retrieved on July 11/2011 from: http://pareonline.net/getvn.asp?r=7\&n=3.

Murugaiah, P. (2016). Pecha Kucha Style PowerPoint Presentation: An Innovative Call Approach to Developing Oral Presentation Skills of Tertiary Students. Teaching English with Technology, 16 (1), 88 - 104.

O'sullivani, B. (2012). Assessing Speaking. Inc. Coombe, P. Davidson, B. O'sullivan, and S. Stoynoff (Eds). The Cambridge Guide to Second Language Assessment, PP. 234 - 246. New York: Cambridge University Press.

Ounis, M. (2017). A Comparison between Holistic and Analytic Assessment of Speaking. Journal of Language Teaching and Research. Vol. 8, No. 4, Pp. 679-690.

Pan, M. (2016). Nonverbal Delivery in Speaking Assessment. From an Argument to Rating Scale Formulation and Validation. Singapore: Springer.

Park, T. (2004). An overview of Portfolio-based Writing Assessment. Retrieved on July 14/2011 from:

http://www.tc.columbia.edu/acedemic/tesol/wjfileds/pdf /Taejoonpark forum.pdf

Parsons, L. (2004). Grammarama! Innovative Exercises, Creative Activities, Models from Reading, Sentence Combining, Updated Rules and More! Ontario: Pembroke Publisher. 
The Effectiveness of Using the Analytic Scoring Approach on Developing the Speaking Skills of the Candidates for the IELTS Exam

Po Krivca Kova, S. (2010). Modern Teacher of English Nitra: ASPA. Publication 1249252009 .

Qian, D.D. (2009). Comparing Direct and Semi- Direct Modes for Speaking Assessment: Affective Effects on test Takers. Language Assessment Quarterly, 6, 113-125.

Read, J. and Nation, P. (2002). An Investigation of the Lexical Dimension of the IELTS Speaking Test IELTS. Research Reports, 6, 1-25.

Richardsm, J., and Schmidt, R. (2013). Longman Dictionary of Language Teaching and Applied Linguistics ( $4^{\text {th }} \mathrm{ed}$.). New York: Routledge.

Roshan, S. (2013). A critical Review of the Revised IELTS Speaking Test. International Journal of English Language Education, Vol. 2,No.1.

Segalowitz, N. (2010). Cognitive Bases of Second Language Fluency. New York: Routledge.

Taylor, L. and Galaczi, E. (2011). Scoring Validity. In L. Taylor (Ed.), M. Milanovic and C. Weir (Series Eds.). Studies in Language Testing 30. Examining Speaking. Research and Practice in Assessing Second Language Speaking. Cambridge: Cambridge University Press. Pp. 171-233.

Taylor, L., and Jones, N. (2001). Revising the IELTS Speaking Test. Research Notes, 5,9-12. Retrieved from

Thombury, S. (2005). Beyond the Sentence: Introducing Discourse Analysis. Oxford: Macmillian.

Tomita, H. (1996). Recent Advances in Parsing Technology. New York: Springer. www. IELTS. Org/PDF/Vol.6-Report2.PDF.

Weir, C.J. (2005). Language Testing and Validation: An Evidence-Based Approach. Houndgravo, Hampshire: Palgrave Macmillan. 


\section{Sally Mohamed Saad El-Din Mostafa}

\section{Appendix (A)}

The IEITS Speaking Test Sample

Familiar questions to help the examiners relax:

Section (1):

(2-3 minutes)

- Introduce yourself.

- Do you like your study / job ?

- Why did you choose that major?

- Describe your hometown.

- How many friends do you have? How do you spend your time with your friends?

Section (2):

(4-5 minutes)

These topics were discussed; they were written on cards, language learners were given one minute to prepare their ideas:

1) Are parents the best teachers? Why / Why not?

2) Describe a custom from your country.

3) Which is better from your own perspective to live in a big city or in a small town? Why?

Section (3):

(7-8 minutes)

Open discussion between the instructor and the examinee.

1) Should teenagers work ? Do you believe in this idea? Why / Why not?

2) Is money the most important aspect in searching for a job? Answer according to your own point of view, and your country's culture.

3) Has fashion changed our lives, Or have we affected fashion?

In other words, Who has the greater influence, People on fashion or vice versa?

4) Does the place where we live, either a city or a town affect our style of wearing and thinking ? Why / Why not ?

5) To how much extent do you believe in this ? 
The Effectiveness of Using the Analytic Scoring Approach on Developing the Speaking Skills of the Candidates for the IELTS Exam

\section{Appendix (B)}

Observation Scoring Sheet

Name:

Date:

Score:

\begin{tabular}{|l|c|c|c|c|c|c|}
\hline \multicolumn{1}{|c|}{ Skill } & $\begin{array}{c}\text { Doesn' } \\
\mathbf{t} \\
\text { attend }\end{array}$ & Poor & Fair & $\begin{array}{c}\text { Goo } \\
\text { d }\end{array}$ & $\begin{array}{c}\text { Very } \\
\text { Goo } \\
\text { d }\end{array}$ & Excellent \\
\hline 1) Appropriateness & 0 & 1 & 2 & 3 & 4 & 5 \\
\hline $\begin{array}{l}\text { 2) Organization of } \\
\text { ideas }\end{array}$ & 0 & 1 & 2 & 3 & 4 & 5 \\
\hline 3) Fluency & 0 & 1 & 2 & 3 & 4 & 5 \\
\hline $\begin{array}{l}\text { 4) Grammatical } \\
\text { structures and accuracy }\end{array}$ & 0 & 1 & 2 & 3 & 4 & 5 \\
\hline 5) Vocabulary & 0 & 1 & 2 & 3 & 4 & 5 \\
\hline 6) Pronunciation & 0 & 1 & 2 & 3 & 4 & 5 \\
\hline
\end{tabular}

- General comments:

- Suggestions for improvement: 
Also these instructions for scoring helped the instructor and the language learners on implementing the strategy of peer evaluation:

\section{1) Appropriateness:}

Sociolinguistically and socioculturally appropriate use of a given discussion.

\section{2) Organization of ideas:}

The extent to which the response is organized in a coherent manner, cohesion between sentences and the idea is successfully achieved through the use of logical connectors and cohesive devices.

\section{3) Fluency:}

Was the speech generally well-connected and fluent?; Did the speaker use the natural fillers?; Did he use any idioms?; Did he speak formally or he used informal language?; Did he use transitions?; Had the speaker the ability to manage his response with regard to openings, closings, turn takings and other interactional practices?

\section{4) Grammatical accuracy and structures:}

To what extent was the speaker (examinee) accurate in using grammar or vocabulary?; To what extent was he / she able to manage the complexity of the sentence? (use a variety of sentence types; simple and complex varied lengths and structures; well constructed and varied structures; accurate and effective use of prepositional phrases, pronouns and determiners; accurate and elaborative use of tenses in active or passive voices.

\section{(5) Vocabulary:}

Did the speaker use a variety of synonyms, or did he practice a high standard vocabulary? ; To what extent did the examinee use the descriptive language?; Was he / she expressing his ideas figuratively or literally? ; To what extent did the speaker use the idioms? ; Was the speaker able to express his ideas within a rhetorical meaning?

\section{6) Pronunciation:}

How was the speaker perfect in pronouncing the words? ; What about the examinee's utterance of words and accent? ; How many mistakes did the speaker make while being examined? (These mistakes were related to mispronunciation from one side and stressed or unstressed syllables in words from the other side). 
The Effectiveness of Using the Analytic Scoring Approach on Developing the Speaking Skills of the Candidates for the IELTS Exam

\section{Appendix (D) \\ Speaking Rubric}

\begin{tabular}{|c|c|c|c|c|c|}
\hline Skills & $\begin{array}{c}\text { Full evidence } \\
5\end{array}$ & $\begin{array}{c}\text { Good } \\
\text { evidence } \\
4\end{array}$ & $\begin{array}{l}\text { Adequate } \\
\mathbf{3}\end{array}$ & $\begin{array}{c}\text { Marginal } \\
\text { evidence } \\
2\end{array}$ & $\begin{array}{c}\text { Limited } \\
\text { evidence } \\
1\end{array}$ \\
\hline $\begin{array}{l}\text { 1) } \\
\text { Appropriateness }\end{array}$ & $\begin{array}{l}\text { Full evidence } \\
\text { of appropriate } \\
\text { use of } \\
\text { discussion } \\
\text { marker in the } \\
\text { conversation. }\end{array}$ & $\begin{array}{l}\text { Good } \\
\text { evidence of } \\
\text { appropriate } \\
\text { use of } \\
\text { discussion } \\
\text { marker in the } \\
\text { conversation. }\end{array}$ & $\begin{array}{l}\text { Adequate } \\
\text { evidence of } \\
\text { appropriate } \\
\text { use of } \\
\text { discussion } \\
\text { marker in the } \\
\text { conversation. }\end{array}$ & $\begin{array}{l}\text { Marginal } \\
\text { evidence of } \\
\text { appropriate use } \\
\text { of discussion } \\
\text { marker in the } \\
\text { conversation. }\end{array}$ & $\begin{array}{l}\text { Limited evidence } \\
\text { of appropriate use } \\
\text { of discussion } \\
\text { marker in the } \\
\text { conversation. }\end{array}$ \\
\hline $\begin{array}{l}\text { 2) Organization of } \\
\text { ideas }\end{array}$ & $\begin{array}{l}\text { - Uses } \\
\text { cohesion in } \\
\text { such a way } \\
\text { that it } \\
\text { attracts no } \\
\text { attention. } \\
\text { - Skillfully } \\
\text { manages } \\
\text { speaking. } \\
\text { - Sequences in } \\
\text { formation } \\
\text { and ideas } \\
\text { logically. }\end{array}$ & $\begin{array}{l}\text { - Uses a } \\
\text { range of } \\
\text { cohesive } \\
\text { devices } \\
\text { appropriate } \\
\text { ly although } \\
\text { there may } \\
\text { be some } \\
\text { under / } \\
\text { over use. } \\
\text { - Arranges } \\
\text { informatio } \\
\text { n and ideas } \\
\text { coherently } \\
\text { and there } \\
\text { is a dear } \\
\text { overall } \\
\text { progressio } \\
\text { n. }\end{array}$ & $\begin{array}{l}\text { - Presents } \\
\text { informatio } \\
\mathrm{n} \text { with } \\
\text { some } \\
\text { organizatio } \\
\mathrm{n} \text { but there } \\
\text { may be a } \\
\text { lack of } \\
\text { over all } \\
\text { progressio } \\
\text { n. } \\
\text { - Makes } \\
\text { inadequate } \\
\text {, } \\
\text { inaccurate } \\
\text { or overuse } \\
\text { of } \\
\text { cohesive } \\
\text { devices. }\end{array}$ & $\begin{array}{l}\text { - Presents } \\
\text { information } \\
\text { and ideas but } \\
\text { these are not } \\
\text { arranged } \\
\text { coherently } \\
\text { and there is } \\
\text { no dear } \\
\text { progression in } \\
\text { the response. } \\
\text { - Use some } \\
\text { basic cohesive } \\
\text { devices but } \\
\text { these may be } \\
\text { inaccurate or } \\
\text { repetitive. }\end{array}$ & $\begin{array}{l}\text { - Doesn't } \\
\text { organize ideas } \\
\text { logically. } \\
\text { - Use a very } \\
\text { limited range of } \\
\text { cohesive } \\
\text { devices, and } \\
\text { those used may } \\
\text { not indicate a } \\
\text { logical relation } \\
\text { ship between } \\
\text { ideas. } \\
\text { - Has a little } \\
\text { control of } \\
\text { organizational } \\
\text { features }\end{array}$ \\
\hline
\end{tabular}

